\title{
CAPACIDAD DE LAS TIERRAS PARA USO AGRÍCOLA EN LA SUBCUENCA MEDIA-ALTA DEL RÍO PIRRÍS, LOS SANTOS, COSTA RICA ${ }^{1}$
}

\author{
Miguel Chinchilla ${ }^{2 / *}$, Alfredo Alvarado ${ }^{* *}$, Rafael Mata ${ }^{* *}$ \\ Palabras clave: Capacidad de uso, tierras agrícolas, Los Santos, Talamanca. \\ Keywords: Land capability, land use, Los Santos, Talamanca.
}

Recibido: 03/06/10

\section{RESUMEN}

El uso de la tierra en la subcuenca mediaalta del río Pirrís, está diferenciado por la altitud sobre el nivel del mar. Entre los 1075 y 1700 $\mathrm{m}$ de elevación, la principal actividad agrícola es el cultivo del café, desarrollado sobre suelos arcillosos del orden de los Ultisoles con importantes manifestaciones de erosión. Por encima de los $1700 \mathrm{~m}$ y hasta los $3100 \mathrm{~m}$ dominan los Andisoles, Inceptisoles y Entisoles, utilizados con bosques, pastos, frutales de altura, algo de hortalizas, floricultura, piscicultura, hoteles de montaña, producción de carbón en trincheras y donde existe menor pérdida de suelo. En general, el área se caracteriza por las tierras montañosas con fuerte pendiente (30 a 60\%) y unos pocos relieves suaves que ocupan valles profundos con terrazas recientes. Rasgos visibles permitieron estimar que en suelos agropecuarios hay un $60 \%$ de erosión moderada (laminar y en surcos) y un $18 \%$ de severa a muy severa, sin considerar una erosión lineal que se presenta por caminos mal diseñados, ausencia de cunetas, excavaciones para infraestructura y deslizamientos activos que provocan remociones de suelo en grandes proporciones. En cuanto a profundidad efectiva, los suelos profundos significan el $44 \%$ del

1 Este trabajo forma parte de la tesis de maestría del primer autor.

2 Autor para correspondencia. Correo electrónico: mchinchillaa@ice.go.cr
Aceptado: 22/03/11 
área, mientras que un $38 \%$ son moderadamente profundos y el $17 \%$ son poco profundos a superficiales. Las calicatas localizadas en la parte media alta de la subcuenca señalan un $33 \%$ de suelos con fertilidad baja y $52 \%$ de fertilidad muy baja. Considerando los factores pendiente, erosión actual visible, fertilidad y profundidad de suelos, la capacidad de uso de las tierras agrícolas en el área estudiada, revela que $1 \%$ de las tierras son clase III; $2 \%$ clase V; $8 \%$ clase VIII; $26 \%$ clase VII y $63 \%$ de clases IV y VI.

\section{INTRODUCCIÓN}

Los métodos de clasificación de uso de la tierra a nivel mundial se estiman entre 30 y 50 , aunque los más usados son entre 12 y 15 (Sharma 1992). Entre los sistemas, unos son más simples que otros, en el sentido de que pueden utilizar solo 2 variables diferenciadoras de las clases, como propuso Plath (1967), al considerar la temperatura y la precipitación como parámetros diferenciadores, o Sheng (1971), al emplear solo la pendiente y profundidad del suelo. Sin embargo, otros sistemas consideran un mayor número de variables tanto edáficas como climáticas y de relieve (Beek 1978, Molina y Sharma 1993, INAB 1999). El sistema más utilizado internacionalmente es el desarrollado por el Departamento de Agricultura de los Estados Unidos (Klingebiel y Montgomery 1961), en el cual las tierras se agrupan de acuerdo con las limitaciones relativas que determinan el rendimiento o la posibilidad de cultivar una especie en forma intensiva. Una variante de este sistema de clasificación de tierras se conoce como la metodología oficial de Costa Rica (MAG-MIRENEM 1995), sistema propuesto para cultivos de secano, sin contemplar los cultivos bajo riego ni aspectos relacionados con tierras de vocación urbanística. Posteriormente se incorporan Sistemas de Información Geográfica (SIG) que apoyan la toma de decisiones con captura, almacenamiento, análisis y modelación de datos (Saborío 1992, Stoorvogel 1996) y modelos peats all over the region show that $33 \%$ the soils are of low fertility and $52 \%$ of very low fertility. Considering relief features, suffered erosion, soil fertility, and soil depth, land use capability for agricultural activities in the watershed are: $1 \%$ Class III, 2\% Class V, 8\% Class VIII, 26\% Class VII, and 63\% Classes IV and VI.

computacionales que interpretan información agroecológica mediante datos georeferenciados para la evaluación de tierras (Arroyo 1996, Ugalde 1996).

Para la toma de decisiones en cuanto al manejo de la subcuenca del río Pirrís, el ICE trabaja en integrar con SIG, la capacidad de uso de la tierra con otras bases de datos en suelos, geología, geomorfología, hidrogeología, red hídrica, uso actual de la tierra, zonas de vida, climatología, acuíferos, división político administrativa, información censal y red vial. Al considerar que la subcuenca del río Pirrís forma parte del Plan Nacional de Expansión Eléctrica que el ICE tiene para suplir la demanda eléctrica requerida por el país y es una región productora del café conocido como grano de oro, de cultivos de altura y de otras actividades económicas de Costa Rica, se ha establecido el objetivo general de: "Identificar la capacidad de uso las tierras en agricultura para la parte media-alta de la cuenca, específicamente aguas arriba del embalse y sitio de presa del P.H. Pirrís" y los objetivos específicos de: "Confeccionar un mapa por capacidad de uso de las tierras" e "Identificar y evaluar las principales limitantes edáficas en el área aguas arriba de la presa del P.H. Pirrís".

\section{Variables en el área de estudio}

1. Generalidades: La cuenca número 26 río Parrita, al sur del Valle Central, conformada 
por las subcuencas de los ríos Pirrís y Grande de Candelaria, es un escenario de actividad agropecuaria desarrollada en paisajes montañosos, que amerita su estudio, ordenamiento y sostenibilidad ambiental. El área del presente estudio se localiza en la subcuenca de río Pirrís, entre las coordenadas $9^{\circ} 36^{\prime}$ y $9^{\circ} 43^{\prime}$ latitud norte y $83^{\circ} 51^{\prime}$ y $84^{\circ} 06^{\prime}$ longitud oeste y es donde se ubica el Proyecto Hidroeléctrico Pirrís (P.H. Pirrís) del Instituto Costarricense de Electricidad (ICE). Aguas arriba de la presa del proyecto, la subcuenca tiene un área de $245 \mathrm{~km}^{2}$, un ancho de $10 \mathrm{~km}$ y un largo de 30 km (IGN 1962, 1963, 1989, 1994), es conocida como la zona de los Santos y cuenta con servicios básicos de agua potable, luz eléctrica, teléfono, escuelas, colegios, sedes universitarias y centros de atención médica. Sus accesos son la carretera Interamericana Sur con dirección de noroeste a sureste y en el interior existen carreteras asfaltadas, calles de lastre transitables todo el año y caminos privados muy deteriorados en áreas de fuerte pendiente. En ella se encuentran los cantones de Santa María de Dota, San Marcos de Tarrazú y San Pablo de León Cortés.

\section{Ocupación antrópica y cambios de} uso del territorio: Muestras de carbón a 110 $\mathrm{cm}$ de profundidad y contenidos en sedimentos del lacustre glacial, indican que las tierras altas de Costa Rica (Cerro Chirripó), han sido objeto de incendios durante los pasados 4000 años algunos por actividad humana, actividad atmosférica como rayos o ambos (Horn 1989). Los fragmentos de carbón se han datado con radiocarbono $\left({ }^{14} \mathrm{C}\right)$ en edades entre $1110 \mathrm{y}$ 2430 años, siendo ello indicio de incendios en el páramo durante el Holoceno (Horn y Sanford 1992). Similares dataciones de polen y carbón provenientes de la Cordillera de Talamanca en un bosque lluvioso montano de la región Chiriquí, Panamá evidencian presencia humana hace 2860 años (Behling 2000).

En el bosque montano bajo y premontano, la deforestación se inicia en el siglo XIX como resultado de la colonización que introduce el cultivo del café en 1850 (Kappelle y Juárez
1995). De acuerdo con Ureña (1992), los primeros cambios en el uso del suelo en Santa María ocurrieron a partir de 1864, aunque la colonización se inició algunos años antes en San Marcos, cuando se realizó la primera tala de bosque primario. Alrededor de 1888 se trajo la primera semilla de café a la región y a los pocos años después se recoge la primera cosecha, en 1929 se instaló el primer beneficio y en 1960 el actual beneficio de Coopedota. La deforestación reciente de las tierras con bosque montano alto en Costa Rica se inicia con la construcción de la carretera interamericana sur en 1941 y con la llegada de finqueros al área (van Omme et al. 1997); el cambio inicial de bosques a pastos, provocó la compactación de los suelos, lo que afectó seriamente su potencial productivo y la calidad del agua (Kappelle et al. 1995). Sin embargo, la degradación de los ecosistemas naturales del área ha disminuido en las últimas 3 décadas (Kappelle y Juárez 1995) con la creación de reservas forestales y la introducción del ecoturismo, actividades que han estimulado a la población local a la conservación del bosque (van Omme et al. 1997). De acuerdo con Pedroni (1991), el área localizada a lo largo de la carretera interamericana entre los poblados de El Empalme y Villa Mills, es de gran potencial para la producción de carbón con propósitos energéticos, pero con una regulación forestal y aprovechando exclusivamente los residuos de los bosques del genero Quercus y el empleo de hornos de metal portátiles para reducir el impacto ambiental causado por el método tradicional de trincheras. Al estudiar el efecto de la zona de vida y la altitud sobre la mortalidad y adaptabilidad de varias especies forestales en la zona de estudio, Badilla et al. (2002), demuestran que el ciprés (Cupressus lusitanica) y el pino pátula (Pinus patula) tienen baja mortalidad y son muy estables, mientras que el roble (Q. coopeyensis) tiene una mejor probabilidad de subsistir en los pisos más altos. Estas consideraciones son importantes si se pretende mejorar el uso de la tierra con sistemas agroforestales. 
3. Ictiofauna: Desde el 2006 hasta el presente (Barrantes y Solano 2007, 2009, 2010) se encontró que en la cuenca del río Pirrís, existen peces desde Copey hasta la desembocadura del río Pirrís en el Estero Boca Parrita. En Copey se encuentra la trucha que es una especie introducida. En la parte media de la cuenca se encuentran principalmente olominas (familia Poecilidae) y chupapiedras (familia Gobiidae). En la parte baja de la cuenca (desde Casa de Máquinas hacia abajo), la diversidad es relativamente alta, encontrándose aproximadamente, 24 especies de agua dulce y 64 especies en total (incluyen especies algunas estuarinas). La mayor diversidad y abundancia se encuentra en los tributarios de la parte baja de la cuenca (quebrada Surubres y río Candelaria), albergan todas las especies de agua dulce que se encuentran en el cauce principal.

4. Zonas de vida y uso de la tierra: Con promedios de precipitación de 1953 a 2048 mm anuales (ICE 2007) y diversas zonas de vida (Chinchilla et al. 2011a), la región exhibe un territorio dominado por el cultivo de café en la parte media y por bosques, pastos, frutales de altura, algo de desarrollo hortícola, floricultura, piscicultura, ecoturismo y producción de carbón en trincheras en la parte alta (Figura 1). Entre los 3100 a los $1075 \mathrm{~m}$, la subcuenca muestra 3 regiones con diferentes uso de la tierra: 1) de los 3100 a $2500 \mathrm{~m}$ hay bosques, potreros con árboles dispersos y producción de carbón en trincheras; 2) entre los 2500 y $1700 \mathrm{~m}$, el uso es más variado y está compuesto por potreros, frutales de altura (manzana, aguacate, ciruela, mora), pequeñas superficies con hortalizas, flores, algunas plantaciones de café y relictos de bosque fragmentado y 3) de los 1700 a los 1075 $\mathrm{m}$, el café es el cultivo más frecuente que inicia en los alrededores de Santa María de Dota y se convierte en dominante para los cantones de Tarrazú y León Cortés.

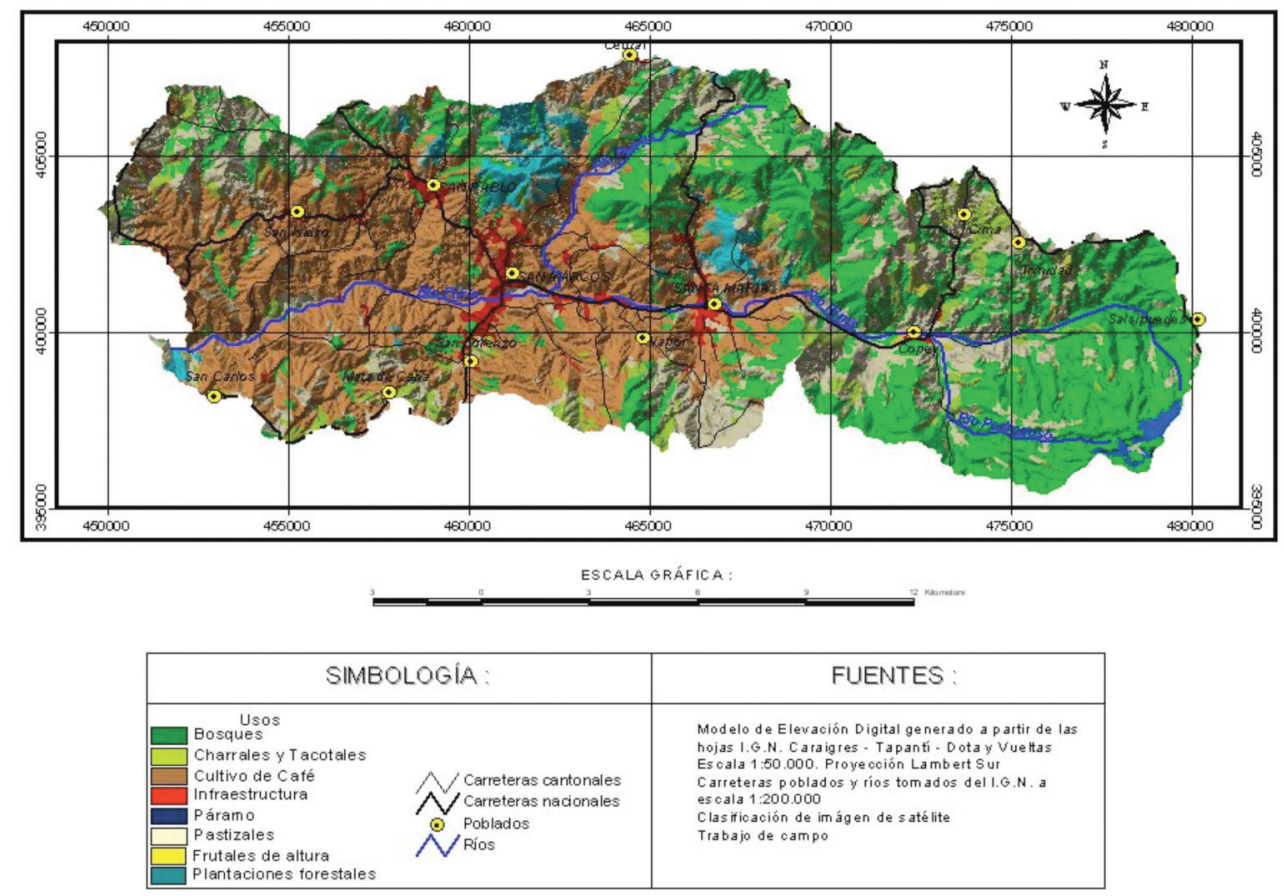

Fig. 1. Uso de la tierra en la subcuenca media alta del río Pirrís. 
5. Geología y suelos: De geología heterogénea (Mora et al. 1985, Arias 2000), la subcuenca alcanza $3100 \mathrm{~m}$ en el límite superior y $1075 \mathrm{~m}$ en el sitio de presa del P.H Pirrís (IGN 1962, 1963, 1989, 1994), una geomorfología de origen tectónico, erosivo y de sedimentación coluvio aluvial (Mora et al 1985), tiene formas del terreno con predominio de laderas que obedecen a la actividad tectónica que provoco el levantamiento de la cordillera de Talamanca, a la actividad volcánica y los movimientos en masa ocurridos en la región. El mosaico edáfico es complejo y variado (Chinchilla et al. 2011a), en las partes más altas y húmedas hay suelos negros y pardos, algunos desarrollados a partir de cenizas volcánicas, frágiles, de baja fertilidad, ácidos, que alternan con suelos superficiales, amarillos y afloramientos rocosos. En las partes medias predominan los suelos arcillosos, meteorizados, de colores rojizos, de baja fertilidad y ácidos, que pueden encontrarse junto con otros suelos menos evolucionados y superficiales.

6. Tierras. Con los primeros trabajos en clasificación de suelos en Costa Rica a inicios del siglo XX, se da paso a la planificación técnica del uso de la tierra (Alvarado 1996), sin embargo, algunos autores (Vahrson 1991, Vásquez 1996, Bertsch 2006) consideran que en las últimas 5 décadas, el uso del territorio costarricense fue afectado por políticas económicas, que aunque permitieron el surgimiento de diversas actividades agrícolas, también condujeron en numerosas ocasiones, a un rompimiento de las fronteras agrícolas sin planificación, lo que causa desequilibrios ecológicos, pérdida de buenas tierras agropecuarias, conflictos de uso de la tierra, transporte de sedimentos que provocan inundaciones, dañan infraestructuras (represas hidroeléctricas, carreteras, sistemas de drenaje), arrastre de plaguicidas y nutrimentos a sistemas de drenajes y costeros, así el asentamiento de poblaciones en áreas vulnerables a deslizamientos e inundaciones (ICE 2007).
La ubicación de los suelos en paisajes montañosos sometidos a una alta precipitación, de texturas finas, drenajes internos lentos, caminos mal diseñados, falta de cunetas, inadecuado manejo de tierras y aguas y existencia de cultivos en áreas de fuerte pendiente, han favorecido la erosión y la pérdida de nutrientes, afectando la calidad ambiental y a la futura infraestructura hidroeléctrica.

\section{MATERIALES Y MÉTODOS}

Para el estudio de la subcuenca se utilizaron hojas topográficas del Instituto Geográfico Nacional (Vueltas 1962, Tapantí 1963, Caraigres 1989, Dota 1994) y fotografías aéreas del Proyecto Carta (2003), entre las coordenadas $9^{\circ} 36^{\prime}$ y $9^{\circ} 43^{\prime}$ latitud $\mathrm{N}$ y $83^{\circ} 51^{\prime}$ y $84^{\circ} 06^{\prime}$ longitud O. Se realizó un levantamiento libre con barreno tipo holandés hasta $120 \mathrm{~cm}$ de profundidad y se abrieron calicatas. En estas se efectúo el muestreo por horizonte genético, se describió el color de suelo en húmedo (Munsell 2000), espesor, estructura, poros, raíces y se anotaron coordenadas, elevación, gradiente, material parental, fisiografía, zona de vida del sitio (USDA-NRCS 2002). En el laboratorio, una parte de las muestras se seco al aire y se tamizó en una criba de $2 \mathrm{~mm}$. Se determinó el $\mathrm{pH}$ en $\mathrm{H}_{2} \mathrm{O}$, la acidez intercambiable por extracción con cloruro de potasio, la materia orgánica con el método de Walkley y Black (1938), la capacidad de intercambio catiónico con $\mathrm{NH}_{4} \mathrm{OAc} 1 \mathrm{~N}, \mathrm{pH}$ 7, los cationes intercambiables $(\mathrm{Ca}, \mathrm{Mg}, \mathrm{K}, \mathrm{Na})$ por extracción con acetato de amonio y determinación espectrofotometría de absorción atómica (Henríquez et al. 1995). Además, la textura de suelo se determinó por el método de Bouyoucos (Forsythe 1985), la densidad aparente mediante muestra volumétrica (Forsythe 1985), la densidad de partículas con el método del Picnómetro (Blacke 1965 en Forsythe 1985), la retención de humedad con ollas de presión de Richards (1941) y la conductividad hidráulica con el método de cilindro de metal (Henríquez y Cabalceta 1999). Con lo anterior, se realizo la clasificación por capacidad de uso de la tierra (MAG-MIRENEM 
1995) y la fertilidad del suelo de acuerdo con Bertsch (1998).

La clasificación de tierras utilizó la metodología para determinar capacidad de uso de la tierra (MAG-MIRENEM 1995) propuesta para cultivos de secano. Este sistema utiliza 8 clases y 4 subclases definidas por una letra minúscula donde indican limitaciones específicas de suelo (s); de erosión (e); de drenaje (d) y de clima (c). De igual manera, contempla unidades de manejo con números arábigos como subíndice, los que son una subdivisión de las subclases y que indican los factores específicos que limitan la utilización de las tierras en actividades agropecuarias y forestales. Las clases se identifican con números romanos, lo que aumenta las limitaciones o el riesgo de erosión del terreno al pasar de la clase I a la clase VIII. Las clases I, II y III permiten el desarrollo de cualquier actividad e incluyen la producción de cultivos anuales cuya selección depende de criterios socioeconómicos. El uso de las clases IV, V y VI se restringe al desarrollo de cultivos semipermanentes y permanentes, con posibilidad de sembrar cultivos anuales en forma ocasional solamente en a clase IV. La clase VII tiene limitaciones tan severas que solo se permite el manejo del bosque natural primario o secundario y en el caso de tierras denudadas debe procurarse el restablecimiento de la vegetación natural. La clase VIII la conforman terrenos que no permiten ninguna actividad productiva agrícola, pecuaria o forestal, ya que es adecuada únicamente para la protección del recurso natural (Figura 4).

\section{RESUTADOS Y DISCUSIÓN}

Pisos altitudinales y uso de la tierra: En las partes altas y medias de la cuenca, el uso de la tierra es muy dinámico, debido a que varía con el piso altitudinal. Entre los 3100 y $2500 \mathrm{~m}$ de altitud, los ecosistemas naturales de bosques siempre verdes son dominados por robledales: Quercus copeyensi (roble blanco), Quercus costaricensis (roble negro), Quercus seemannii (roble encino), hay especies del genero Chusquea y ecosistemas culturales de Pennisetum clandestinum (kikuyo) con árboles dispersos del genero Quercus, hoteles de montaña y extracción de carbón en sistema de trincheras. De los 2500 y 1700 m se observan más los ecosistemas culturales con frutales de altura: Persea americana (aguacate Hass), Prunus persica (ciruelas), Malus sp (manzana), Rubus sp (mora silvestre), Passiflora sp (granadillas) y potreros de P. clandestinum (kikuyo); otros cultivos comunes son: Solanum tuberosum (papa), Daucus carota (zanahoria), Apium graveolens (apio), Allium schoenoprasum (cebollinos), junto con la Rosa spp (rosa) y Oncorhynchus mykiss (Trucha arco iris), plantaciones forestales de Cupressus sp (ciprés) y Alnus acuminata (jaúl) y relictos de bosques con Quercus, Ocotea spp (aguacatillo) y Ulmus mexicana (tirrá), entre otros. En la parte media de la subcuenca (1700 y $1100 \mathrm{~m}$ ) dominan los cafetales (Coffea arabica); cuando existe sombra en la plantación de café, es común el uso de los géneros Musa (plátano, guineo, banano) y Erythrina (poró). En el perímetro y en el interior de las parcelas también se hallan árboles frutales de Citrus (naranjas, limones), Eriobotrya japonica (nísperos) Annona cherimolia (anona), Psidium guajava (guayabo), Spondias purpurea (jocote) y Persea americana (aguacates); algunos árboles comunes son el Cecropia obtusifolia (guarumo), Croton draco (targuá) y Ochroma pyramidale (balsa).

En comparación con lo encontrado en el presente trabajo, varios autores (Kappelle y Juarez 1995, INBio 2001), identifican 3 pisos altitudinales: Premontano (500 a $1200 \mathrm{~m}$ ), Montano Bajo (1200 a $2300 \mathrm{~m})$ y Montano Alto (2300 a $3100 \mathrm{~m})$. Los pisos mencionados por Kappelle y Juarez (1995) casi coinciden en límites para el piso alto y medio del presente estudio (3100$2500 \mathrm{~m}$ y $2500-1700 \mathrm{~m}$, respectivamente), aunque difieren en el límite inferior del piso bajo de la cuenca media del río Pirrís (1700 y 1100 m) del presente estudio.

Clasificación de los Suelos: De acuerdo con Chinchilla et al. (2011a), en el área hay 4 grandes unidades edáficas: 1) en partes altas del relieve, los poblados del Jardín, Quebradillas, 
Cañón, La Cima, Trinidad presentan suelos derivados de cenizas volcánicas, frágiles, muy erodables, susceptibles a deslizarse, que pertenecen al orden de los Andisoles e Inceptisoles (Chinchilla et al. 2011 c). La textura de estos suelos es moderadamente gruesa en superficie a moderadamente fina y fina en el subsuelo, el drenaje externo es rápido por pendiente y el drenaje interno varía de rápido a lento en superficie y lento en el subsuelo, lo que favorece la escorrentía superficial con pérdida del horizonte $\mathrm{A}$; 2) en partes medias del relieve que incluyen en mucho a los cantones de Tarrazú y León Cortés, dominan los suelos desarrollados sobre superficies geológicas antiguas y terrazas antiguas, clasificados en Chinchilla et al. (2011b) dentro del orden de los Ultisoles. En general estos suelos son moderadamente profundos a profundos, texturas finas y muy finas, ácidos, fertilidad baja, plásticos y adherentes, con muy escasa retención de agua y baja disponibilidad de agua en épocas de sequía, además de conductividades hidráulicas lentas en el subsuelo que favorecen la perdida de los horizontes A; 3) en las partes medias-altas del relieve, cerca de lugar conocido como los Quemados y en las laderas al Norte de Copey de Dota, existen suelos del orden de los Inceptisoles y Entisoles (Chinchilla et al. 2011c). Los Inceptisoles son muy ácidos y de muy baja fertilidad desarrollados sobre materiales intrusivos ácidos, sus texturas son moderadamente finas, además de ser poco profundos a superficiales, con pedregosidad en superficie y a través del perfil y un drenaje externo rápido por pendiente que favorece la erosión y; 4) en las partes bajas del relieve, valles y terrazas aluviales de los poblados de Santa María y Copey de Dota, se presentan los suelos derivados de materiales aluviales recientes de los fondos de valle, clasificados como Inceptisoles y Entisoles (Chinchilla et al. 2011c). Son suelos de acidez fuerte a ligera, texturas moderadamente gruesas a moderadamente finas, baja capacidad de retención de agua por lo que pueden presentar una marcada necesidad de este en épocas de déficit hídrico.
Los suelos mencionados, también han sido descritos con anterioridad en la zona por varios autores (Harris 1971b, Holdridge et al. 1971, Landaeta et al. 1978, Otarola y Alvarado 1977, Sancho y Núñez 1985, Blazer y Camacho 1991, van UFFELEN 1991, ICAFE -CIA 2000).

Fertilidad de los suelos: De acuerdo con Chinchilla et al. (2011a), 52\% de los suelos estudiados tienen suma de bases menor a $5 \mathrm{cmol}(+) . \mathrm{l}^{-1}$ y saturación de acidez mayor a 50\% que significa fertilidad muy baja, el $33 \%$ son de fertilidad baja con suma de bases menor a $5 \mathrm{cmol}(+) . \mathrm{l}^{-1} \mathrm{y}$ saturación de acidez menor a 50\% (Cuadro 1).

Cuadro 1. Clases de fertilidad en la subcuenca media alta del río Pirrís.

\begin{tabular}{lcc}
\hline Clases de fertilidad & ha & $\%$ \\
\hline Alta & 1091 & 4 \\
Media & 2598 & 11 \\
Baja & 8205 & 33 \\
Muy Baja & 12640 & 52 \\
Total & 24536 & 100 \\
\hline
\end{tabular}

A nivel de cuenca se encontró que el pH en agua tiene un valor promedio de 5,17 (fuertemente ácido), con un valor máximo de 6,4 y mínimo 4,1. El 76\% de las muestras del horizonte A son de $\mathrm{pH}$ menor a 5,5 y de este porcentaje, el $42 \%$ es menor a pH 5,0. Los horizontes B y C tienen $68 \%$ de $\mathrm{pH}$ menor a 5,5 y de este porcentaje, el $29 \%$ de las muestras son menores a 5,0. La acidez intercambiable promedio es $2,47 \mathrm{cmol}(+) .1^{-1}$ (alto), con un máximo de $27,7 \mathrm{cmol}(+) . .^{-1}$ suelo y mínimo de $0,15 \mathrm{cmol}(+) \mathrm{l}^{-1}$ suelo. El $67 \%$ de los horizontes A, $\mathrm{B}$ y $\mathrm{C}$ tienen acidez intercambiable mayor que 1 cmol(+). $l^{-1}$, considerada como muy alta. Solo un $11 \%$ de horizontes A y $14 \%$ de horizontes B y C tienen acidez inferior a $0,3 \mathrm{cmol}(+) .1^{-1}$. El porcentaje de saturación de acidez promedio fue de $36 \%$ (normal), su máximo 95\% y mínimo 0,76\%. El $47 \%$ de las muestras de los horizontes A tienen un porcentaje de acidez intercambiable mayor a 
$30 \%$ y el $24 \%$ tienen una saturación de acidez menor a $10 \%$.

El promedio de calcio extraíble es 5,90 cmol(+). $\mathrm{l}^{-1}$ (medio), su máximo de $25 \mathrm{cmol}(+) . \mathrm{l}^{-1}$ y mínimo de $0,1 \mathrm{cmol}(+) \cdot \mathrm{l}^{-1}$. El $67 \%$ de las muestras del horizonte A son inferior a $4 \mathrm{cmol}(+) .1^{-1}$. Similar situación se observa en los horizontes B y C. Los valores óptimos se presentaron en $16 \%$ de las muestras de horizontes A y $11 \%$ de horizontes B y C. El magnesio extraíble promedio es 1,29 cmol (+). $1^{-1}$ (medio), el máximo 4,92 cmol(+). $1^{-1}$ y mínimo $0,01 \mathrm{cmol}(+) .1^{-1}$. Únicamente el $9 \%$ de los horizontes A y el $8 \%$ de los horizontes B y C tienen valores óptimos de magnesio. La deficiencia de $\mathrm{Mg}$ la presenta un $53 \%$ de las muestras de los horizontes A y $71 \%$ de los horizontes B y C. El potasio extraíble promedio es $0,33 \mathrm{cmol}(+) \cdot 1^{-1}$ (medio), máximo 1,6 cmol(+). $\mathrm{l}^{-1}$ y mínimo 0,07 cmol(+). $1^{-1}$. En superficie, $42 \%$ de las muestras tuvieron valores medios. El subsuelo es más deficiente y alcanza solo el $11 \%$ de las muestras. El 86\% de las muestras del horizonte A y el $93 \%$ de los horizontes $\mathrm{B}$ y $\mathrm{C}$ tienen valores que varían de medios a bajos. El $44 \%$ de las muestras del horizonte A es menor a $0,2 \mathrm{cmol}(+) .1^{-1}$, y el $82 \%$ de los horizontes B y C. La CICE promedio fue $9,72 \mathrm{cmol}(+) .1^{-1}$ (medio), con un máximo de 29 cmol(+). $1^{-1}$ y mínimo $0,44 \mathrm{cmol}(+) \cdot \mathrm{l}^{-1}$. La CICE dominante varía de media a baja. Valores medios de CICE (5 a $10 \mathrm{cmol}(+) .1^{-1}$ ) ocurren en $38 \%$ de muestras superficiales y $39 \%$ del subsuelo. El $33 \%$ de horizontes A y el $26 \%$ del subsuelo tienen una CICE menor que $5 \mathrm{cmol}(+) . \mathrm{l}^{-1}$.

El fósforo promedio es $15 \mathrm{mg} . \mathrm{l}^{-1}$ (normal), con un máximo $101 \mathrm{mg} . \mathrm{l}^{-1}$ y mínimo $1 \mathrm{mg} . \mathrm{l}^{-1}$. El $68 \%$ de las muestras superficiales son bajas $(<12$ mg..$\left.^{-1}\right)$ y solamente el $14 \%$ presenta valores óptimos (20 a 50 mg..$^{-1}$ ). El zinc promedio es de 3,10 mg. $1^{-1}$ (normal), con un máximo de $21 \mathrm{mg} . \mathrm{l}^{-1} \mathrm{y}$ mínimo 0,2 mg. $\mathrm{l}^{-1}$. El 57\% de los suelos son bajos en superficie $\left(<2 \mathrm{mg} \cdot \mathrm{l}^{-1}\right)$. Solo un $27 \%$ presentaron valores de entre 3 y 10 mg. $\mathrm{l}^{-1}$ considerados como óptimos. El cobre tiene un valor promedio normal de 7,09 mg. $\mathrm{l}^{-1}$ (normal), su valor máximo es 20,4 mg..$^{-1}$ y mínimo $1 \mathrm{mg} . \mathrm{l}^{-1}$. El 95\% de las muestras están entre 1 y $20 \mathrm{mg} .1^{-1}$ considerados como óptimos. El hierro promedio es 268,2 mg. $\mathrm{l}^{-1}$ (alto), con un máximo de $975 \mathrm{mg} . \mathrm{l}^{-1}$ y mínimo $47 \mathrm{mg} . \mathrm{l}^{-1}$. Los valores mayores a 50 mg. $\mathrm{l}^{-1}$ representan $98 \%$ de los horizontes A analizados. Solo un $2 \%$ son óptimos. El manganeso tiene un valor promedio de 42,45 mg. $\mathrm{l}^{-1}$ (alto) un máximo de $620 \mathrm{mg} . \mathrm{l}^{-1} \mathrm{y}$ mínimo $1 \mathrm{mg} . \mathrm{l}^{-1}$. Un 52\% de muestras superficiales son óptimos (10 a $50 \mathrm{mg} . \mathrm{l}^{-1}$ ). Valores menores a $5 \mathrm{mg} . \mathrm{l}^{-1}$ ocurren en $30 \%$ de las muestras analizadas. En la Figura 2 se muestran algunos valores químicos de los suelos estudiados.

Las baja fertilidad encontrada, se debe a la presencia en el área de grandes unidades litológicas sedimentarias y volcánicas del Plioceno al Mioceno, a las terrazas de sedimentación coluvial levantadas por la tectónica de la Cordillera de Talamanca y a los materiales erosionados de intrusivos ácidos presentes en el área (Mora et al. 1985, Kussmaul 1987, Drummond et al. 1995, Arias 2000). De igual forma, las cenizas datadas en 590 \pm 95 años por Harris (1971) en las partes altas del relieve y depositadas sobre horizontes argílicos ácidos del Pleistoceno, generaron los Andisoles ácidos, con baja fertilidad encontrados en la región estudiada; en este caso los suelos se lavan con facilidad debido a su alta permeabilidad. Los suelos hallados en los fondos de valle de Santa María y Copey de Dota son de buena fertilidad, atribuida posiblemente al enriquecimiento natural por minerales arrastrados desde las laderas sur y noreste de esos poblados. Por su parte, la presencia de intrusivos ácidos del Plioceno, de mineralogía primaria rica en cuarzo, plagioclasas sódicas y feldespáticos potásicos (Kussmaul 1987, Drummond et al. 1995), se asocian con suelos de muy alta acidez y bajo contenido de bases. Algunos estudios de fertilidad en la región de Los Santos, muestran problemas de fertilidad en suelos cafetaleros, donde destaca la fuerte acidez y el bajo contenido de bases (ICAFE-CIA 2000, Chaves et al. 2008, Chaves et al. 2009) y concuerdan con lo encontrado en la parte media de la subcuenca por el presente estudio. Lo anterior sumado a la erosión en los cafetales, hace que estas tierras no sean sostenibles ni a mediano ni a largo plazo. 

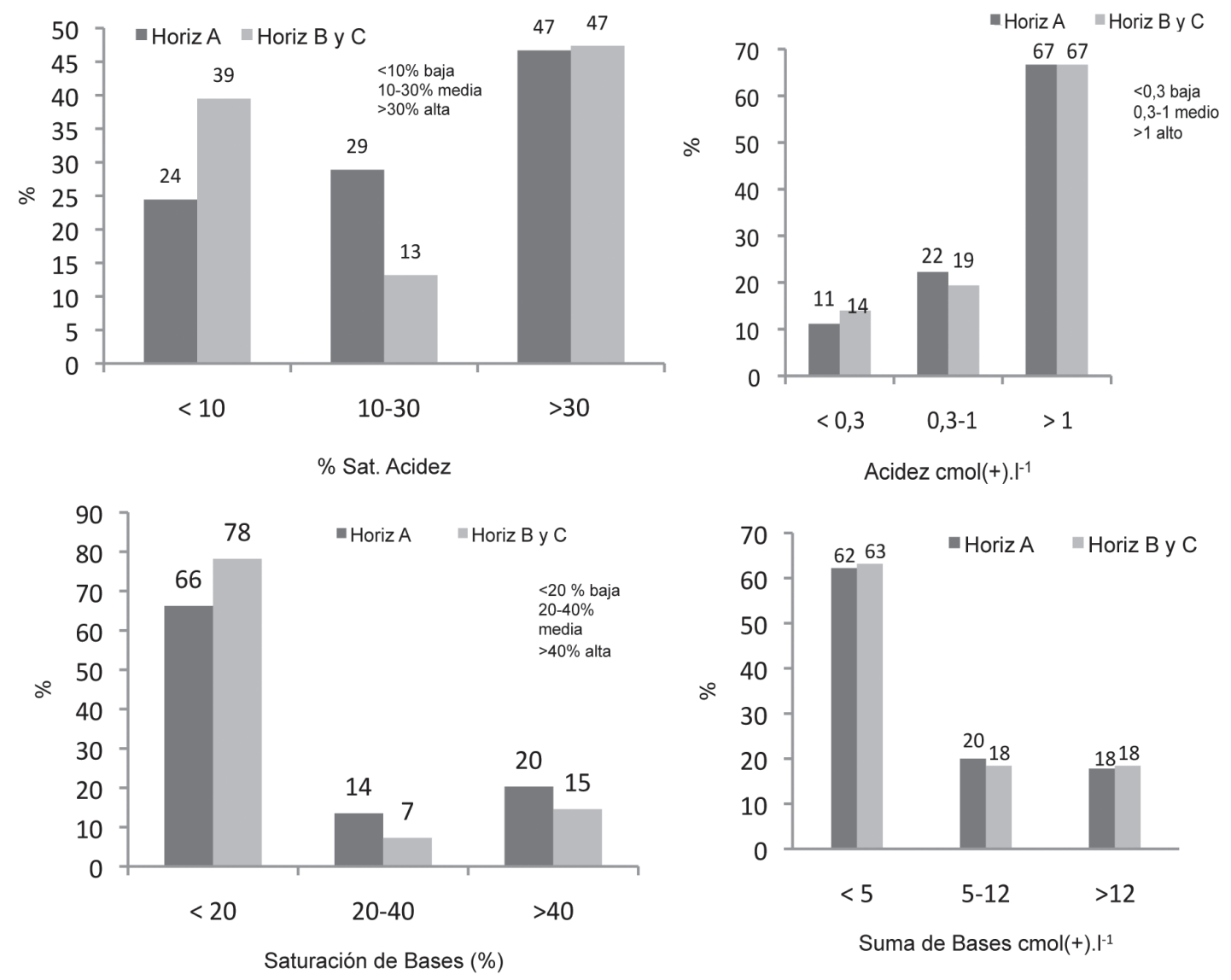

Fig. 2. Valores químicos en la subcuenca media alta del río Pirrís.

Como la fertilidad de los suelos es baja o muy baja en el $87 \%$ de los terrenos, se considera que el potencial de la tierra para la producción o diversificación de cultivos en la zona es muy restringida. Desde el punto de vista de conservación de suelos, esta es una limitante severa, ya que los habitantes de la región no tienen muchas posibilidades de diversificar su economía basada en agricultura. Desde el punto de vista de erosión, además la cobertura del suelo es mínima, lo que a su vez elevaría la escorrentía y por ende las tasas de erosión en las áreas cultivadas.

Manejo y Erosión de los Suelos: Sin cuantificar la pérdida de suelo y con daños visibles como pérdida del horizonte A, presencia de surcos, acúmulo de sedimentos en cambios de pendiente, pedestales, raíces expuestas, se estimó que la erosión actual es moderada en 14755 ha (60\%), severa a muy severa en 4297 ha (18\%) y ligera en 5485 ha (22\%) (Cuadro 2).

En la parte media de la subcuenca se observa un mayor impacto de la erosión lineal por caminos mal diseñados, falta de superficies de rodamientos, excavaciones para obras civiles, incorrectos manejos de suelos y agua, así como por deslizamientos de diversa magnitud (Figura 3).

Dentro del área estudiada, algunos autores (ICE 2006, Solano 2010) cuantificaron la pérdida de suelo de tolerable a moderada. El ICE (2006) 
Cuadro 2. Clases de erosión en la subcuenca media alta del río Pirrís.

\begin{tabular}{lcc}
\hline Clase de erosión & ha & $\%$ \\
\hline Ligera & 5485 & 22 \\
Moderada & 14755 & 60 \\
Severa y muy severa & 4297 & 18 \\
Total & 24537 & 100 \\
\hline
\end{tabular}

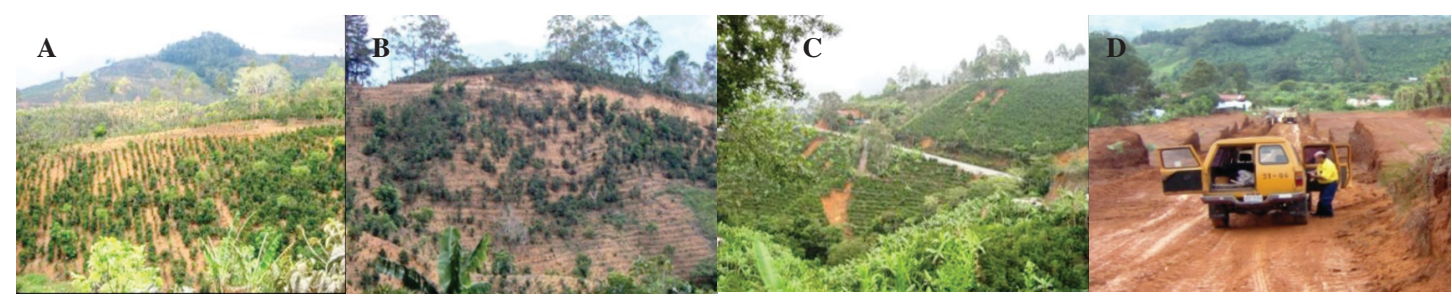

Fig. 3. Áreas en producción de sedimentos. A. La siembra a favor de pendiente favorece la escorrentía superficial y arrastre de sedimentos hasta cauces naturales. B. Laderas sin cobertura vegetal aumentan la pérdida del horizonte A. C. Deslizamientos de diferente magnitud en áreas cafetaleras donde falta manejo de aguas. D. Construcción de caminos e infraestructura en suelos arcillosos, con eliminación de cobertura y escorrentía superficial.

estimó en el año 1996, una carga de sedimento en suspensión afluente al futuro embalse del P.H. Pirrís de 7,26 t.ha ${ }^{-1}$.año ${ }^{-1}$ y 10 años después de 8,80 t.ha $^{-1}$.año ${ }^{-1}$, mientras que en el año 2009, plantaciones de café con poca sombra y en pendiente de 30-60\%, tuvieron una pérdida de suelo de 10,9 t.ha- ${ }^{-1}$ año ${ }^{-1}$ (Solano 2010) con tendencia a la destrucción de los suelos y a una baja en los rendimientos de las tierras. Varios autores sugieren que para reducir la escorrentía superficial, la erosión y mejorar la retención de nutrientes en el suelo es necesario implementar el adecuado manejo de los suelos (Bermúdez 1980, Vahrson y Palacios 1993, Hernández et al. 1997, Sancho y Cervantes 1997, Beer et al. 1998, Arellano 2000, Da Matta y Rodríguez 2007). Con el fin de reducir las tasas de erosión en la parte media de la cuenca, donde dominan las plantaciones de café, se considera necesario implementar o mejorar las prácticas de cultivo recomendadas por el ICAFE (ICAFE 1998, Ramírez 2009).
Pendientes: La región tiene un predominio de tierras montañosas de fuerte pendiente, con áreas de relieve suave que ocupan valles y terrazas de pequeña extensión. Las pendientes onduladas, fuertemente onduladas y escarpadas representan el 96\% del área ubicada aguas arriba del embalse en el P.H. Pirrís (Cuadro 3). Nótese que el $73 \%$ de las tierras tienen una pendiente superior al $30 \%$, de las cuales el $10 \%$ son aún

Cuadro 3. Clases de pendientes en la subcuenca media alta del río Pirrís.

\begin{tabular}{lcc}
\hline Clases de pendiente & ha & $\%$ \\
\hline $0-3 \%$ & 248 & 1 \\
$3-8 \%$ & 624 & 2 \\
$8-15 \%$ & 277 & 1 \\
$15-30 \%$ & 5602 & 23 \\
$30-60 \%$ & 15390 & 63 \\
$60-75 \%$ & 2396 & 10 \\
Total & 24537 & 100 \\
\hline
\end{tabular}


más empinadas. Las fuertes pendientes en la región requieren obligatoriamente que existan prácticas de buen uso de la tierra para minimizar la erosión del suelo, por ejemplo la práctica del gabeteo. Es poco lo que se puede mejorar para corregir pendientes superiores al 30\%, excepto la utilización de especies arbóreas que ayuden a mejorar la cobertura del suelo o la construcción de terrazas, que si bien es una labor costosa, es una de las prácticas más recomendables para evitar la erosión del suelo. Se debe utilizar el uso de sombra, siembra en contorno, canales, barreras vivas, así como en el manejo de malezas, no se debería abusar del uso de herbicidas y por el contrario alternar estos con chapias de forma que el suelo no permanezca desnudo.

Textura de los Suelos: Los resultados de textura de los horizontes superficiales indican que el $69 \%$ son moderadamente finos a finos, $28 \%$ medianos y solamente el $3 \%$ de los suelos tienen textura gruesa. En los horizontes subsuperficiales, son arcillosos en $96 \%$ de las muestras analizadas y solo un $2 \%$ tienen texturas medianas y $2 \%$ gruesas, según se observa en el (Cuadro 4). Como mencionan Henríquez y Cabalceta (1999) las texturas arcillosas, tienen tasas de infiltración bajas y por ende favorecen la escorrentía y la pérdida de suelos.

Cuadro 4. Clases de textura en la subcuenca media alta del río Pirrís.

\begin{tabular}{lcc}
\hline Textura & ha & $\%$ \\
\hline & Horizonte superficial & \\
Gruesa & 762 & 3 \\
Media & 6926 & 28 \\
Moderadamente fina & 12636 & 52 \\
Fina & 4212 & 17 \\
Total & 24537 & 100 \\
& Horizonte subsuperficial & \\
Gruesa & 482 & 2 \\
Media & 544 & 2 \\
Moderadamente fina & 10815 & 44 \\
Finas & 12695 & 52 \\
Total & 24537 & 100 \\
\hline
\end{tabular}

Profundidad Efectiva: Un $44 \%$ de los suelos son profundos a muy profundos, el $38 \%$ son moderadamente profundo y el $18 \%$ poco profundos y superficiales (Cuadro 5).

Cuadro 5. Clases de profundidad efectiva en la subcuenca media alta del río Pirrís.

\begin{tabular}{lcc}
\hline Profundidad efectiva & ha & $\%$ \\
\hline Muy profundo & 6590 & 27 \\
Profundo & 4043 & 17 \\
Moderadamente profundo & 9403 & 38 \\
Poco profundo & 2034 & 8 \\
Superficial & 2467 & 10 \\
Total & 24537 & 100 \\
\hline
\end{tabular}

Pedregosidad: El $62 \%$ de los suelos presentan de nula a ligera pedregosidad superficial mientras que el $28 \%$ son moderadamente pedregosos. Un $10 \%$ son pedregosos, muy pedregosos o fuertemente pedregosos (Cuadro 6). La mayoría de las áreas pedregosas en la zona se ubican en terrenos planos en los cuales se puede hacer agricultura intensiva de mora y pastos, por lo que estas tierras son muy apreciadas. Por el contrario, los afloramientos rocosos en terrenos empinados (principalmente sobre materiales Intrusivos) son perjudiciales y no tienen otro valor más que paisajístico.

Cuadro 6. Clases de pedregosidad en la subcuenca media alta del río Pirrís.

\begin{tabular}{lcc}
\hline Pedregosidad & ha & $\%$ \\
\hline Sin pedregosidad & 4232 & 17 \\
Ligera & 11098 & 45 \\
Moderada & 6952 & 28 \\
Pedregoso & 106 & 1 \\
Muy pedregoso & 1418 & 6 \\
Fuertemente pedregoso & 730 & 3 \\
Total & 24537 & 100 \\
\hline
\end{tabular}

Riesgo de Inundación: El 95\% de la subcuenca media alta no presenta riesgo de inundación y solamente el 5\% muestra un riesgo de leve a moderado (Cuadro 7). 
Cuadro 7. Riesgo de inundación en la subcuenca media alta del río Pirrís.

\begin{tabular}{lcc}
\hline Riesgo de inundación & ha & $\%$ \\
\hline Nulo & 23702 & 97 \\
Leve & 586 & 2 \\
Moderado & 248 & 1 \\
Total & 24537 & 100 \\
\hline
\end{tabular}

Uso de la Tierra: El uso de la tierra está determinado por la elevación sobre el nivel del mar. Los ecosistemas culturales predominan debajo de los $2500 \mathrm{~m}$, con plantaciones de café como el cultivo dominante hasta los $1700 \mathrm{~m}$, además de potreros, frutales de altura, hortalizas, flores y piscicultura que se observan hasta los $2500 \mathrm{~m}$ aproximadamente. Por encima de los 2500 y hasta los $3100 \mathrm{~m}$, la parte alta de la subcuenca muestra ecosistemas naturales de bosques siempre verdes con Quercus y Chusqueas y ecosistemas culturales compuestos por pastos y arboles dispersos, hoteles de montaña y extracción en trincheras de carbón principalmente. El uso actual de la tierra muestra una región con prolongada actividad agropecuaria (Cuadro 8).

Cuadro 8. Usos de la tierra en la subcuenca media alta del río Pirrís.

\begin{tabular}{lcc}
\hline Uso de la tierra & ha & $\%$ \\
\hline Bosque & 7472 & 30 \\
Café & 8279 & 34 \\
Charrales y Tacotales & 1546 & 6 \\
Cultivos de altura & 85 & 0,4 \\
Infraestructura & 591 & 2 \\
Forestales & 805 & 3 \\
Pastizales & 5631 & 23 \\
Páramo & 110 & 0,4 \\
Superficies con agua & 8 & 0,1 \\
Tierras yermas & 10 & 0,1 \\
Total & 24537 & 100 \\
\hline
\end{tabular}

Capacidad de Uso: En el Cuadro 9 y Figura 4, se presenta la información general sobre la capacidad de uso de la tierra de la región, donde se reconocieron 6 Clases de Uso: el $1 \%$ es de clase III o sea de vocación agrícola intensiva, el
Cuadro 9. Capacidad de uso de la tierra de la cuenca mediaalta del río Pirrís.

\begin{tabular}{lll}
\hline Clases de uso & ha & $\%$ \\
\hline III & 88 & 1 \\
IV & 4763 & 19 \\
V & 536 & 2 \\
VI & 10741 & 44 \\
VII & 6498 & 26 \\
VIII & 1910 & 8 \\
Total & 24537 & 100 \\
\hline
\end{tabular}

$2 \%$ es de clase $\mathrm{V}$ con vocación ganadera, el $32 \%$ tienen capacidad para uso forestal o conservación (clases VII-VIII) y el restante 63\% tiene vocación para cultivos permanentes clases IV y VI. La Figura 5 muestra el mapa de capacidad de uso de las tierras, escala 1:50 000 con la delimitación de las clases de tierras encontradas. La pendiente, erosión sufrida, profundidad efectiva y fertilidad actual, fueron los parámetros más importantes al evaluar la capacidad de uso de la tierra del área estudiada. El presente trabajo estimó un $96 \%$ de las tierras con relieves de ondulados a fuertemente ondulados y escarpados; un $60 \%$ de erosión moderada (laminar y en surcos); el 56\% de los suelos moderadamente profundos a superficiales y un $88 \%$ de fertilidad baja a muy baja.

Los factores que determinan las unidades de capacidad de uso varían de acuerdo con la clase de capacidad de uso en cuestión. Para la Clase III (terrazas bajas subrecientes en Bajo San Juan y Copey de Dota), se permite cultivos anuales y perennes con prácticas de manejo y conservación de suelos y aguas; las principales limitantes son e12 s234 y su uso requiere cobertura, incorporación de materia orgánica, fertilización, enmiendas y manejo de aguas. La Clase IV (pendientes entre 15-30\% en algunos sectores al norte de la cuenca, como los alrededores de Cedral, Jardín, La Cima, Quebradillas, Vara Blanca, San Pedro y partes centrales sobre depósitos coluviales de las terrazas antiguas en San Marcos y San Lorenzo de Tarrazú), permite cultivos semipermanentes, permanentes y sistemas agroforestales, con labranza mínima, cobertura de suelo, siembra en contorno, barreras vegetales, 

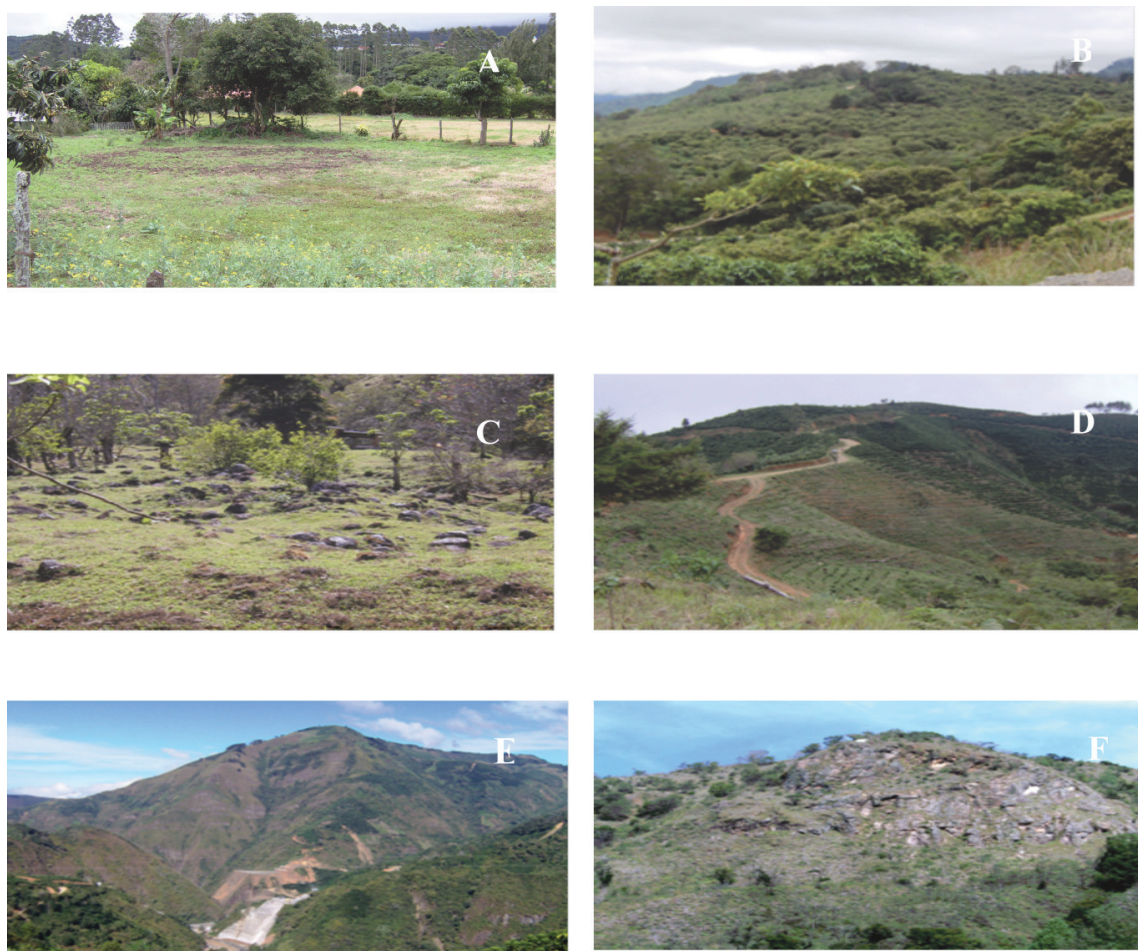

Fig. 4. Ejemplos de tierras de clase III (A), IV (B), V (C), VI (D), VII (E) y VIII (F) en la subcuenca media-alta del río Pirrís.

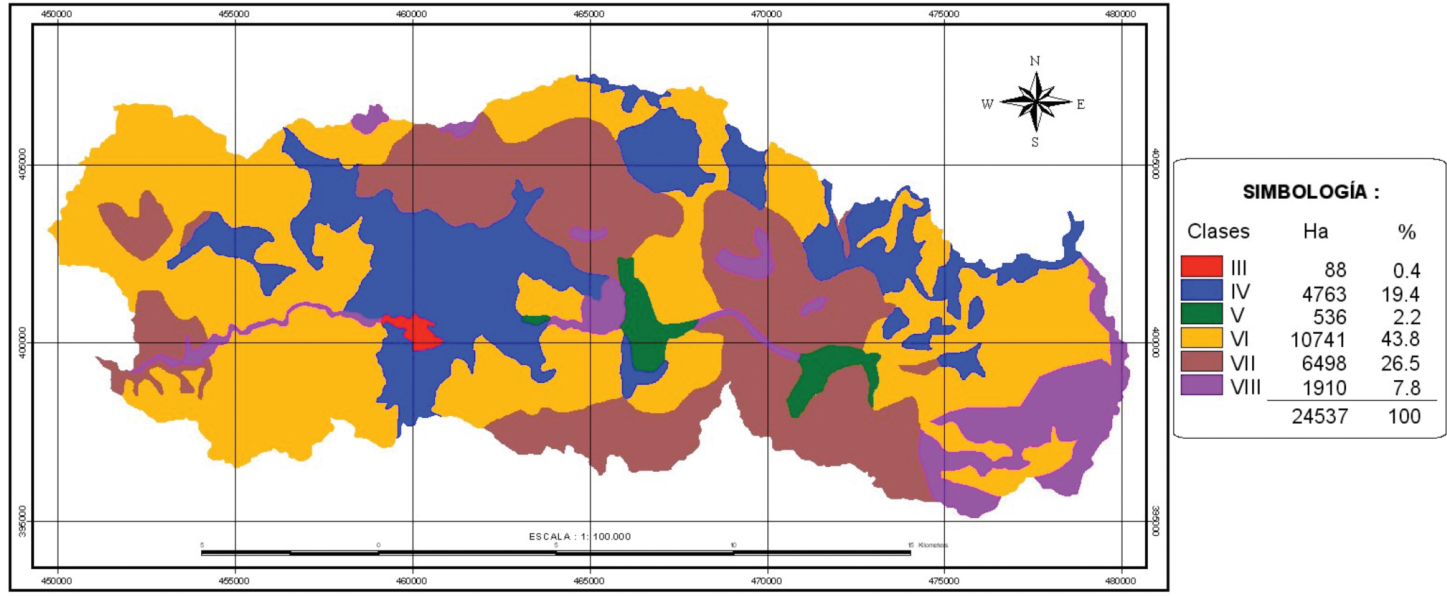

Fig. 5. Mapa de capacidad de uso de la tierra en la subcuenca media alta río Pirrís. 
canales de guardia, acequias de ladera, diseño de caminos, construcción de cunetas, control de cárcavas, diseño y cobertura vegetal de taludes. En cafetales incluir estratos vegetales con el asocio de café y otros cultivos como aguacate, cítricos, musáceas, poró. Los cultivos anuales se pueden desarrollar ocasionalmente con prácticas muy intensivas de manejo y conservación de suelos y aguas. Existe áreas de moderada fertilidad y riesgos de erosión que clasifican como IV e12. Con un horizonte gris oscuro cerca de la superficie como IV e12 d1. De baja fertilidad son IV e12 s4, y si tienen pedregosidad IV e12 s34; cuando son de poca a moderada profundidad se clasificaron como IV e12 s1234.

Clase V: En Copey y Santa María de Dota se ubican terrazas subrecientes de los ríos Pirrís y Pedregoso, con un relieve casi plano a ligeramente ondulado. Las limitantes en estas tierras son la presencia de grava de tamaño diverso en el subsuelo y en algunos casos pedregosidad superficial. Suelos de las terrazas fluviales del río Pedregoso, al norte de Copey, con pedregosidad superficial abundante limitan la preparación de la tierra y clasifican como V s13; cuando existe algún riesgo de inundación se clasificaron como V s13 d1. Tierras que no presentan pedregosidad superficial clasifican como V s1. Son aptos para pastos y actualmente algunos suelos se usan con cultivos semi permanentes y permanentes, observándose buenos resultados. En su utilización, requieren prácticas intensivas de manejo y conservación de suelos y aguas, enmiendas, fertilización, abonos verdes, apartos, ubicación de bebederos, pastos de corta, semiestabulación y sistemas de riego.

Clase VI: Dominan en laderas erosionadas. Suelos profundos con fuertes riesgos de erosión, arcillosos, de baja fertilidad, ácidos se clasificaron en Clase VI e12 s24. Suelos similares pero con áreas pedregosas como Clase VI e12 s234. Los suelos moderadamente profundos, texturas finas, en áreas con pedregosidad, baja fertilidad, ácidos, se clasificaron en Clase VI e12 s1234. Esta clase se observa en la parte media de la cuenca, en los alrededores de Higueronal, La Bandera, Guadalupe, La Pastora, Vara Blanca, San Carlos, Mata de Caña, Zapotal, Llano Bonito, San Isidro, Carrizales, San Pablo y en la parte alta, incluye áreas aledañas a Cedral, Quebradillas, Cañón, La Cima, Trinidad y también se observa en el camino que conduce al Cerro Vueltas.

El manejo de los suelos de esta clase debe poner énfasis en cobertura de suelo y caminos con superficie de rodamiento y cunetas, sin descartar la posibilidad de forestar con especies nativas o exóticas con potencial de acuerdo con el piso ecológico que corresponda (Badilla et al. 2002). Las principales limitaciones de uso en el área para esta clase son el relieve fuertemente ondulado, erosión sufrida, texturas finas a muy finas, baja fertilidad y contenidos altos de aluminio intercambiable. Los problemas de acidez deben ser estudiados mediante investigación y experimentación a nivel de finca. Los riesgos de erosión son muy fuertes por el drenaje externo rápido y el interno lento, siendo condiciones que benefician la escorrentía superficial, la remoción del horizonte A, con arrastre de sedimentos, pérdida de materia orgánica y de nutrientes. Su uso se limita a cultivos permanentes (incluye forestales) pero con prácticas intensivas de conservación de suelos y aguas. Los cultivos anuales deben descartarse. Entre las prácticas recomendadas se tiene: estudio de suelos y planificación agro conservacionista de fincas, manejo de aguas (canal guardia, acequias de ladera), labranza mínima, sistemas agroforestales (especies forestales tolerantes a la acidez), siembra en contorno, barreras vivas, barreras muertas, cobertura muerta (mulching), cultivos de cobertura, enmiendas, abonos verdes, fertilización, control y rehabilitación de deslizamientos, sistemas de riego, diseño de caminos y taludes, drenajes de caminos, protección de taludes, incorporación de materia orgánica. El cultivo del café en asocio con cultivos como el aguacate, cítricos, musáceas y poró son recomendados para promover la protección del suelo con varios estratos vegetales al impacto de 
las lluvias, mejorar la infiltración y la fijación de nitrógeno atmosférico, debe además realizarse incorporarse materia orgánica y se recomienda eliminar el uso de herbicidas en esta clase y utilizar el control mecánico de las hierbas (machete, guadaña).

Clase VII: ocupan superficies con relieve de muy fuertemente ondulado a escarpado con pendientes cercanas a $60 \%$, riesgos de erosión fuertes. En general son suelos de moderada a poca profundidad y drenaje excesivo por pendiente se clasificaron en Clase VII e12 S13 y con muy baja fertilidad y muy ácidos clasifican como Clase VII e12 s134. Suelos similares sin pedregosidad clasifican como VII e12 s14. Son tierras que tienen severas limitaciones por lo que solo permiten el manejo forestal en caso de cobertura boscosa con especies tolerantes a la acidez del suelo, en aquellos casos en que el uso sea diferente al bosque se procurará la restauración forestal por medio de la regeneración natural. Se les observa en laderas al sur de Higueronal, La Bandera, Copey. También suelos desarrollados por la meteorización de rocas intrusivas que se observan en el flanco norte de Copey y Santa María de Dota. En el cantón de Tarrazú, se presentan en algunas laderas norte (Cerro Trinidad) y en áreas vecinas al sitio de presa y Santa Rosa de León Cortés. En el caso de que se decida continuar con la producción de carbón cerca del cerro Vueltas, se recomienda cambiar la tecnología de producción de acuerdo con lo recomendado por Pedroni (1991).

Clase VIII: En esta clase existen suelos de relieves quebrados y planos. Los suelos que se ubican en relieves escarpados son de pendientes entre 60 y $75 \%$, son poco profundos, con la roca afloran cerca de la superficie, pedregosos o de fragmentos rocosos a poca profundidad. En general presentan mala estructuración y alta fragilidad de suelo que los enmarca con tierras con elevado riesgo de erosión. Suelos poco profundos y pedregosos en los Intrusivos clasifican como VIII e12 S13. Con limitaciones de zonas de vida y neblina como VIII e12 c13. En relieve plano, micro relieve irregular, con leve a severo riesgo de inundación se clasifican como VIII d2. El uso de este tipo de tierras es únicamente para la protección del recurso natural, por lo que las actividades como la creación de reservas forestales y la introducción del ecoturismo que mencionan (Kappelle y Juárez 1995, van Omme et al. 1997), son imprescindibles, si se desea revertir el proceso degradativo en estos ecosistemas. Algunas actividades de tipo agrícola asociadas al ecoturismo (por ejemplo, pesca de trucha, cultivo de hongos comestibles, etc.) pueden ayudar a mejorar la economía familiar de los pobladores de la zona, pero no se vislumbran como una alternativa a escala de desarrollo económico social de la región a corto o largo plazo.

Impacto del Proyecto Hidroeléctrico del río Pirrís: Dentro del marco natural discutido (pisos altitudinales, diferencias en tipos de suelos y unidades geológicas, usos de la tierra, capacidad de uso de la tierra, etc.), se introduce en la región de los Santos el P.H. Pirrís. Con esta obra, el ICE realiza un programa de educación ambiental en escuelas de la región sobre reforestación, manejo de desechos (25000 kg de materiales reciclados), biodiversidad y amenazas naturales. Ha construido aceras (34 $000 \mathrm{~m})$; barandas (2356 $\mathrm{m})$; senderos peatonales $(7385 \mathrm{~m})$ reductores de velocidad (25 unidades); mejora de caminos en 117750 m. (Parrita 25 650, Aserrí 20 700, León Cortés 31 550, Tarrazú 39850 m); construcción de puentes ( 6 viales y 1 peatonal); reforzamiento de puentes; estabilización de taludes (26 muros de gavión); manejo de aguas de escorrentía (29 $000 \mathrm{~m}$ en cunetas); mejoramiento de superficies de rodamiento $(12750 \mathrm{~m}$ en asfalto, $4500 \mathrm{~m}$ en tratamiento superficial TS-3 y en concreto tipo RCC $22000 \mathrm{~m}$ ); obras de mantenimiento (superficie de rodamiento, cunetas, alcantarillas, bacheo) y señalamiento de vías (59 $700 \mathrm{~m}$ ). Otras acciones son la construcción y mejoramiento de escuelas, colegios, iglesias, acueductos, salones comunales, áreas deportivas, telesecundaria y mejoramiento de caminos a través de instituciones 
estatales como el Consejo Nacional de Viabilidad (CONAVI) (Figura 6), entre otros.

El ICE ha estudiado las amenazas (naturales y antrópicas) en toda la subcuenca del río Pirrís y formo la Unidad de Manejo de de la Cuenca del río Pirrís (UMCUPI) para implementar un Plan de Manejo. En relación con la contratación de mano de obra, la fase constructiva del proyecto ha ocupado el 5\% del total de la mano de obra del Cantón de Tarrazú, el 2 del cantón de Dota y el 5\% de León Cortés para un total de 1398 empleos ocasionales en la región de los Santos.

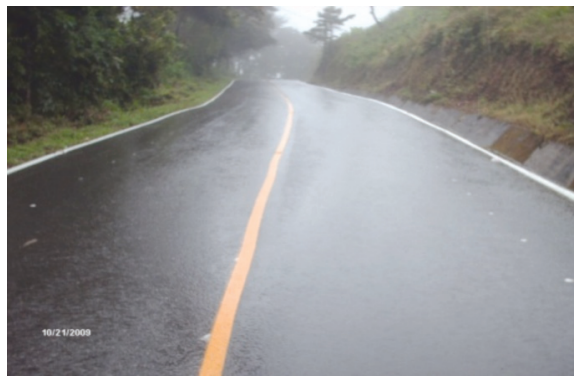

Fig. 6. Ejemplos de antes y después del inicio de la construcción del P.H. Pirrís en el mejoramiento del camino a San Carlos de Tarrazú por el CONAVI. (Fotografía cortesía Ing. Luis Meléndez).

Las acciones mencionadas, tienden a disminuir los efectos negativos que este tipo de intervención humana causa sobre el ambiente y al que se oponen los grupos ambientalistas en todo el mundo. Aún es temprano para evaluar el impacto de la represa sobre los peces en el río Pirrís, los cambios en patrones migratorios de los habitantes de la zona, los cambios en el costo de la vida en la región, entre otros. En relación con los impactos que puedan ocurrir sobre la ictiofauna, a causa de la operación del proyecto podrían asociarse principalmente al acarreo de altas concentraciones de sedimentos durante la ejecución de desembalses. Sin embargo, se espera que en aras del desarrollo sostenible, las previsiones tomadas hasta el momento sean todas positivas.

\section{CONCLUSIONES}

Los suelos son un componente importante de la subcuenca que se deben proteger para lograr la sostenibilidad ambiental en la misma.

En la zona de los Santos se ha generado un deterioro ambiental, asociado principalmente a prácticas de uso de la tierra, ausencia de técnicas para controlar erosión, perdida de la cobertura vegetal deforestación y características de las tierras. En el uso de las tierras agrícolas de la parte media alta de la subcuenca, la pendiente, profundidad efectiva del suelo, erosión y fertilidad fueron parámetros determinantes.

Las pendientes fuertemente onduladas son una de las limitantes de uso más preponderante de la subcuenca. Sumado a lo anterior, los suelos son en un 55\% moderadamente profundos, poco profundos y superficiales.

La fertilidad de los suelos es baja a muy baja en el $85 \%$ de las muestras estudiadas. Esto indica la necesidad de emplear fertilizantes con un balance adecuado de nutrientes y la necesidad de incentivar el uso de enmiendas calcáreas para corregir problemas de acidez existentes conforme con los análisis del laboratorio de suelos.

En el área de estudio se presentan altas precipitaciones con alta intensidad de la lluvia, que sumado a las fuertes pendientes se favorecen las escorrentías superficiales, la falta de cobertura vegetal de suelo, texturas arcillosas, caminos mal diseñados, inadecuados manejos de agua en caminos y en fincas, son algunos disparadores para el transporte de sedimentos y de elementos 
químicos presentes en el suelo hasta los cauces naturales existentes dentro de la Cuenca.

El grado de erosión moderada a severa y muy severa ha alcanzado un $78 \%$ de las tierras de la subcuenca de un área estudiada de 24 536,61 ha.

La Capacidad de Uso de la Tierra mostró que únicamente el $1 \%$ de las tierras son de vocación agrícola intensiva clases III; el 63\% tiene vocación para cultivos permanentes clases IV y VI; el $26 \%$ de las tierras son de vocación forestal, y solo el $2 \%$ es de vocación ganadera.

A pesar de su susceptibilidad a la erosión, la compactación, la fertilidad baja, la deficiencia de humedad aprovechable durante época seca, el relieve quebrado y la profundidad radicular, algunos sectores de las partes altas tienen tierras que permiten la agricultura y la ganadería, siempre y cuando se realicen las prácticas de conservación de suelos adecuadas.

Los relieves existentes y la alta precipitación (1954 a $2233 \mathrm{~mm}$ anuales), sumados a texturas finas y muy finas, drenaje interno de suelo lento, han favorecido la escorrentía superficial, el arrastre de sedimentos y nutrientes que se pierden desde las fincas e implican pérdidas económicas para los productores de la región.

Algunos otros factores que contribuyen con la pérdida de suelo son los movimientos telúricos, las quemas, los caminos de finca mal diseñados, ausencia de superficie de rodamiento, inadecuados manejos de agua. A lo anterior se debe añadir la infraestructura que durante sus construcciones eliminan la cobertura vegetal.

Se estima que la mayor erosión de suelos ocurre en la parte media de la subcuenca, donde el café es predominante, por lo que su cultivo requiere de las prácticas de manejo en plantaciones cafetaleras recomendadas por el Instituto del Café de Costa Rica (ICAFE 1998, Ramírez 2009).

\section{RECOMENDACIONES}

Al considerar que el café es el principal cultivo en la región media de la subcuenca, donde se estima ocurre la mayor erosión, se presentan características de baja fertilidad y fuerte acidez, resulta de especial importancia el manejo que los caficultores realicen de sus plantaciones. De acuerdo con el ICAFE (1998) y Ramírez (2009) las prácticas más recomendables son: incentivar el uso de enmiendas calcáreas que ayuden a corregir la acidez del suelo y el empleo de fertilizantes con un balance adecuado de nutrientes. Por otra parte, las fuertes pendientes requieren obligatoriamente que existan prácticas de buen uso de la tierra, que minimicen la erosión del suelo en las fincas cafetaleras, tales como: uso de sombra, cobertura viva, cobertura con residuos vegetales o "mulch", siembra en contorno, barreras vivas, canales, construcción de cajas colectoras de aguas de escorrentía, control de deslizamientos. Para el manejo de malezas, no se debe abusar del uso de herbicidas y por el contrario alternar estos con chapias de forma que el suelo no permanezca desnudo. Finalmente, en los suelos que lo permitan por su consistencia, la construcción de terrazas, que si bien es una labor costosa, es una de las prácticas más recomendables para evitar la erosión del suelo y lograr un mejor aprovechamiento de los fertilizantes.

Al considerar que la degradación de los suelos afecta la calidad ambiental, el rendimiento de los suelos y el arrastre de sedimentos en la subcuenca, los actores que intervienen en la misma deben enfocar la problemática dentro y fuera de las fincas, mediante alianzas estratégicas entre las municipalidades cooperativas e instituciones estatales e iniciar con un proyecto de "Control de la erosión en la zona cafetera de la región de los Santos", considerada como el área de mayor impacto en cuanto al aporte de sedimentos dentro de la subcuenca.

Se debe promover la investigación sobre la contribución de la biomasa y la materia orgánica del suelo de los cafetales, en el secuestro de carbono. Si se reconociera la fijación de carbono a productores de café, podría incentivarse la conservación y control de la erosión de los suelos cafetaleros. 
Al buscar favorecer la calidad ambiental, disminuir la erosión y la pérdida de nutrientes, se debe considerar una subvención que lleve a los agricultores a dejar de sembrar en áreas de fuerte pendiente, y eliminar el café de tierras clase VIII. Como opción para las tierras de fuerte pendiente ocupadas actualmente con cafetales, es incentivar las líneas de producción de café orgánico y se apoye la inserción de estas tierras cultivadas a los mercados externos. Se sugiere detener la expansión cafetalera en tierras clase superior a la VI. La Clase VII, con severas limitaciones para el uso agropecuario se propone explotarlos únicamente con manejo forestal y con regeneración natural. Las tierras Clase VIII, debe ser para preservar la flora y la fauna, áreas de recarga acuífera y belleza escénica.

En las zonas de mayor pendiente, se debe conservar la vegetación original, o si esta ha sido talada hay que emprender acciones de reforestación. Algunos ejemplos de especies forestales son enumeradas por Badilla et al. (2002).

Eliminar áreas de café ubicadas en clases VII y VIII, con alto grado de erosión, todo a cambio de un subsidio de parte del ICE que recompense por la disminución de los rendimientos de café, lo que asegura que se reducirán las pérdidas por erosión (y por ende de solvatación de la represa).

En los caminos existentes dentro y fuera de las fincas cafetaleras se necesitan superficies de rodamiento, construcción y mantenimiento de cunetas para evacuar las aguas de escorrentía, con amarre vegetativo y control de deslizamientos de los taludes. Mantener una "cerca viva" o franja natural de árboles y arbustos a lo largo de los caminos y carreteras. Que el ICE promueva un programa regional dentro de la subcuenca, para el mantenimiento de taludes y caminos vecinales, que son de los problemas de mayor impacto en cuanto a erosión de suelo se refiere. La obra de ingeniería eléctrica disminuirá la llegada de sedimentos a su embalse en el tanto se logre conservar el suelo en su sitio, aunque no debe descartarse que siempre habrá erosión de suelos por razones naturales.
Se deben proteger las riberas de ríos en la región con una franja de al menos $5 \mathrm{~m}$ de ancho a cada lado de los riachuelos pequeños y de $10 \mathrm{~m}$ a lo largo del río y realizar el control de cárcavas, deslizamientos y evitar que el terreno en la región este descubierto de vegetación.

En general, a nivel de subcuenca, las tierras agrícolas con pendientes mayores que $15 \%$ (Clase IV) deben tener prácticas agro conservacionistas y mecánicas con sistemas de explotación que combinen plantaciones forestales, agricultura permanente, establecimiento de varios estratos vegetativos en las parcelas, cobertura vegetal del suelo, manejo y conservación de aguas. Debe promoverse que en estas tierras exista la siembra en contorno, se elimine el uso de herbicidas y realizar la corta de hierbas manualmente, favoreciendo la cobertura muerta (mulching) con incorporación de materia orgánica al suelo.

Para las tierras onduladas de la Clase V, se recomienda su explotación sistemática a través de apartos para el pastoreo controlado, pastos mejorados, pastos de corta, semi estabulación, con el fin de prevenir el desperdicio cualitativo del pastizal. También se pueden utilizar cultivos semipermanentes (mora) y permanentes (café) dado que el lecho de grava puede ocurrir a $50 \mathrm{~cm}$ de profundidad.

En las tierras en relieve fuertemente ondulado con pendientes mayores que 30\%, clasificadas en Clase VI, es posible la siembra de cultivo perenne (frutal y café) y producción forestal e implementar prácticas intensivas de manejo y conservación de suelos y aguas. Si el uso es de cafetales, debe promoverse el café bajo sombra con leguminosas (poró), guineo, plátano, banano, aguacate y otros que integren un estrato superior con las matas de café e intercepten las lluvias antes de su impacto directo con el suelo, se suministre nutrientes mediante la fijación de nitrógeno, aumenten la incorporación de materia orgánica, contribuyan con la infiltración de agua a través del perfil de suelo, aumente la biodiversidad, el equilibrio ecológico para atenuar incidencias de plagas y enfermedades, esto con 
el fin de recuperar el equilibrio natural, al diversificar el sistema.

Los promedios de las características químicas de los suelos de la subcuenca muestran suelos ácidos de acuerdo con lo siguiente: $\mathrm{pH}$ bajo, aluminio intercambiable alto, porcentaje de saturación de bases bajo, deficientes en calcio, magnesio, potasio, fósforo, zinc, lo que se traduce en fertilidad actual a baja (Bertsch 1998). Consecuentemente la fertilización sostenida y el encalado periódico en función de los análisis de un laboratorio de suelos, deben constituirse en prácticas corrientes de manejo aplicadas en forma controlada y adaptadas al tipo de uso de la tierra, incluyendo los pastizales. El manejo de la acidez debe investigarse mediante ensayos a nivel de finca. Promover la utilización de fertilizantes elaborados en las fincas tipo compost, bocashi, lombricompost, uso de microorganismos efectivos, etc., con ensayos en la finca para el cálculo de la dosis que se debe aplicar por planta.

\section{LITERATURA CITADA}

ALVARADO A. 1996. El papel del estudio de suelo en la agricultura costarricense, pp. 1-5. In: Congreso Nacional Agronómico y de Recursos Naturales (10), Congreso Nacional de Fitopatología (3), Congreso Nacional de Suelos (2). ¿Puede la agricultura sostenible ser competitiva?: memoria. F. Bertsch, W. Badilla, E. Bornemisza (eds). San José, CR, EUNED/EUNA, v.3.

ARELLANO R. 2000. Pérdida de suelo y nutrientes en agroecosistemas de café en la subcuenca del río Castán, Trujillo-Venezuela. Revista Forestal Venezolana 44(2):79-86.

ARIAS O. 2000. Geología y petrología magmática del Bloque Herradura (Cretácico Superior - Eoceno, Costa Rica). Tesis Ph.D, Universidad de Lausanne, Suiza. 186 p.

ARROYO L. 1996. Método de evaluación de tierras para cultivos anuales, por medio del sistema de información geográfica: estudio de caso (Distrito de Upala), pp. 29-37. In: Memoria Congreso Nacional Agronómico y de Recursos Naturales (10), Congreso Nacional de Fitopatología (3), Congreso Nacional de Suelos (2). ¿Puede la agricultura sostenible ser competitiva?, F. Bertsch, W. Badilla, E. Bornemisza (eds). San José, CR, EUNED/EUNA, v.3.

BADILLA Y., MURILLO O., OBANDO G. 2002. Efecto de la zona de vida y la altitud en la mortalidad y adaptabilidad al primer año de especies forestales en la Cordillera Volcánica Central, Costa Rica. Agronomía Costarricense 26(1):7-15.

BARRANTES R., SOLANO E. 2007. Monitoreo de variables biológicas para el manejo de sedimentos del $\mathrm{PH}$ Pirrís. Centro de Servicio Gestión Ambiental, UEN PySA, ICE. Manuscrito. San José, C.R. 42 p.

BARRANTES R., SOLANO E. 2009. Biodiversidad y uso de hábitat de especies acuáticas asociadas a las subcuencas del los ríos Pirrís, Parrita y Estero Boca Parrita. Centro de Servicio Gestión AmbientalUnidad de Manejo de Cuencas PH Pirrís, UEN PySA, ICE. Manuscrito. San José, CR. 31 p.

BARRANTES R., SOLANO E. 2010. Biodiversidad y uso de hábitat de especies acuáticas asociadas a las subcuencas del los ríos Pirrís, Parrita y Estero Boca Parrita. Centro de Servicio Gestión AmbientalUnidad de Manejo de Cuencas PH Pirrís, UEN PySA, ICE. Manuscrito. San José, C.R. 22 p.

BEEK K.J. 1978. Land evaluation for agricultural development. Some explorations of land use systems analysis with particular reference to Latin America. ILRI, Wageningen, The Netherlands Publ. 23. 333 p.

BEER J., MUSCHLER R., KASS D., SOMARRIBA E. 1998. Shade management in coffee and cacao plantations. Agroforestry Systems 38:139-164.

BEHLING H. 2000. A 2860-year high-resolution pollen and charcoal record form the Cordillera de Talamanca in Panama: a history of human and volcanic forest disturbance. The Holocene 10(3):87-393.

BERMUDEZ M. (1980). Erosión hídrica y escorrentía superficial en el sistema de café (Coffea arabica L.), poró (Erythrina poeppiginia) y laurel (Cordia alliodora) en Turrialba, Costa Rica. Tesis de maestría, CATIE, Turrialba, Costa Rica. 74 p.

BERTSCH F. 1998. La fertilidad de los suelos y su manejo. San José, CR, Asociación Costarricense de la Ciencia del Suelo. 157 p.

BERTSCH F. 2006. El recurso tierra en Costa Rica. Agronomía Costarricense 30(1):133-156.

BLAKE G.R. 1965. Method of soil analysis. Agronomy Monograph, No. 9. pp. 371-377. 
BLASER J., CAMACHO M. 1991. Estructura, composición y aspectos silviculturales de un bosque de robles (Quercus spp.) del piso montano en Costa Rica. Proyecto CATIE/COSUDE, Colección Silvicultura t Manejo de Bosques Naturales $N^{\circ}$. 1. Turrialba, Costa Rica. 68 p.

BOLAÑOS R.A., WATSON V. 1993. Mapa ecológico de Costa Rica: según el sistema de clasificación de zonas de vida del mundo de L.R. Holdridge. San José, CR, Centro Científico Tropical. 1:200 000. Color. (San José CR-2CM-5).

CHAVES V.M., UREÑA J.L., GUZMAN J.A., ALPIZAR Y. 2008. Caracterización de la fertilidad de los suelos dedicados al cultivo de café en Costa Rica: Dota, León Cortés y Tarrazú. San Marcos de Tarrazú, CR. ICAFE. 45 p.

CHAVES V.M., UREÑA J.L., GUZMÁN J.A., ALPÍZAR Y., NUNES A. 2009. Caracterización de la fertilidad de los suelos dedicados al cultivo de café en Costa Rica: II- Los Santos Norte, Aserrí, Acosta, Desamparados, Cartago, Guarco. Heredia, CR. ICAFE. 45 p.

CHINCHILlA M., ALVARADO A., MATA R. 2011a. Factores formadores y distribución de suelos en la subcuenca del río Pirrís, Talamanca, Costa Rica. Agronomía Costarricense. 35(1): 33-57.

CHINCHILlA M., MATA R., ALVARADO A. $2011 \mathrm{~b}$. Caracterización y clasificación de algunos Ultisoles de la región de los Santos, Talamanca, Costa Rica, Costa Rica. Agronomía Costarricense. 35(1): 59-81.

CHINCHILlA M., MATA R., ALVARADO A. 2011c. Andisoles, Inceptisoles y Entisoles de la Subcuenca del rio Pirrís, región de los Santos, Talamanca, Costa Rica. Agronomía Costarricense. 35(1): 83-107.

DaMATTA F., RODRÍGUEZ N. 2007. Producción sostenible de cafetales en sistemas agroforestales del Neotrópico: una visión agronómica y eco fisiológica. Agronomía Colombiana 25(1):113-123.

DRUMMONT M.K., BORDELON M., de BOER J.Z., DEFANT M.J., BELLON H., FEIGENSON M.D. 1995. Igneous petrogenesis and tectonic setting of plutonic and volcanic rocks of the Cordillera de Talamanca, Costa Rica-Panamá, Central American Arc. American Journal of Science 295:875-919.

FORSYTHE W. 1985. Física de suelos: manual de laboratorio. San José, CR, IICA. 212 p.
HARRIS S.A. 1971. Quaternary vulcanicity in the Talamanca range of Costa Rica. Canadian Geographer 15(2):141145 .

HENRÍQUEZ C., BERTSCH F., SALAS R. 1995. Fertilidad de suelo: Manual de laboratorio. San José, CR, Asociación Costarricense de la Ciencia del Suelo. $64 \mathrm{p}$.

HENRÍQUEZ C., CABALCETA G. 1999. Guía práctica para el estudio introductoria de los suelos con un enfoque agrícola. San José, CR, Asociación Costarricense de la Ciencia del Suelo. 112 p.

HERNÁNDEZ R.G., RUIZ A., BARRANTES G. 1997. Degradación de suelos y sus efectos sobre la productividad. Escuela de Ciencias Geográficas. UNA. Heredia. CR. 49 p.

HOLDRIDGE L.R., GRENKE W.C., HATHEWAY W.H., LIANG T., TOSI J. 1971. Forest environments in tropical life zones: a pilot study. New York, USA. $747 \mathrm{p}$.

HORN S.P. 1989. Prehistoric fires in the Chirripó highlands of Costa Rica: sedimentary charcoal evidence. Biología Tropical. 37(2):139-148.

HORN S.P., SANDFORD R.L. 1992. Holocene fires in Costa Rica. Biotrópica 24(3):354-361.

ICAFE (Instituto del Café de Costa Rica). 1998. Manual de recomendaciones para el cultivo del café. San José, CR, ICAFE. 193 p.

ICAFE (Instituto del Café de Costa Rica), CIA (Centro de Investigaciones Agronómicas). 2000. Caracterización de suelos cafetaleros en la región de los Santos. En prensa.

ICE (Instituto Costarricense de Electricidad). 2006. Informe de hidrología. Comisión de manejo de sedimentos de Pirrís. San José, CR, UEN PSA. 8 p.

ICE (Instituto Costarricense de Electricidad). 2007. Estudio de amenazas naturales y antrópicas en la cuenca del Río Pirrís. San José, CR, UEN PSA. 83 p.

IGN (Instituto Geográfico Nacional). 1962. Hoja cartográfica Vueltas (3344 IV). San José, CR, Ministerio de Obras Públicas y Transportes. Esc. 1:50,000. Color.

IGN (Instituto Geográfico Nacional). 1963. Hoja cartográfica Tapantí (3345 III). San José, CR, Ministerio de Obras Públicas y Transportes. Esc. 1:50 000. Color. 
IGN (Instituto Geográfico Nacional). 1989. Hoja cartográfica Caraígres (3345 II). San José, CR, Ministerio de Obras Públicas y Transportes. Esc. 1:50 000. Color.

IGN (Instituto Geográfico Nacional). 1994. Hoja cartográfica Dota (3344 I). San José, CR, Ministerio de Obras Públicas y Transportes. Esc. 1:50 000. Color.

INAB (Instituto Nacional de Bosques, Guatemala, Ministerio de Agricultura, Ganadería y Alimentación, Plan de Acción Forestal para Guatemala). 1999. Clasificación de tierras por capacidad de uso, aplicación de una metodología para tierras de la República de Guatemala. Versión 2.0. Guatemala, Guatemala. 27 p. Guía Técnica del INAB, Nº. 1 .

INBIO (Instituto Nacional de Biodiversidad). 2001. Caracterización de la vegetación de la cuenca del río Savegre. Informe Técnico. Costa Rica. 118 p.

KAPPELLE M., JUAREZ M.E. 1995. Agroecological zonation along an altitudinal gradient in the montane belt of the Los Santos Forest Reserve in Costa Rica, pp. 215-247. In: Ecology of nature and recovering Talamanca montane Quercus Forests, CR. University of Amsterdan.

KAPPELLE M., van UFFELEN J.G., CLEEF A.M. 1995. Altitudinal zonation of montane Quercus forest along two transects in the Chirripó National Park, Costa Rica, pp. 55-106. In: Ecology of nature and recovering Talamanca montane Quercus forest, Costa Rica. University of Amsterdam.

KLINGEBIEL A.A., MONTGOMERY P.H. 1961. Landcapability classification. Agricultural Handbook 210. Soil Conservation Service. U.S.D.A. Gov. Print. Office. Washington, D.C. 210 p.

KUSSMAUL S. 1987. Petrología de las rocas intrusivas neógenas de Costa Rica. Revista Geología América Central 7:83-111.

LANDAETA A., LÓPEZ C.A., ALVARADO A. 1978. Caracterización de la fracción mineral de suelos derivados de cenizas volcánicas de la Cordillera de Talamanca, Costa Rica. Agronomía Costarricense 2(2):117-129.

MAG-MIRENEM (Ministerio de Agricultura y Ganadería; Ministerio de Recursos Naturales Energía y Minas). 1995. Manual para la determinación de la capacidad de uso de las tierras de Costa Rica. Segunda Edición. San José, Costa Rica. 59 p.

MOLINA A., SHARMA P.N. 1993. Validación de una metodología simple para establecer la capacidad y uso apropiado de la tierra en pequeñas fincas de Nicaragua. CATIE, Turrialba. 21 p.

MORA S., VALVERDE R., BRENES G. 1985. Análisis geológico-geomorfológico de la Cuenca del Río Pirrís (Parrita). Cartago, CR, ITCR. 44 p.

MUNSELL COLOR COMPANY. 2000. Munsell soil color charts. USA. s.p.

OTÁROLA C.E., ALVARADO A. 1977. Caracterización y clasificación de algunos suelos del Cerro de la Muerte, Talamanca, Costa Rica. Suelos Ecuatoriales 8(1):397-400.

PEDRONI L. 1991. On the production of charcoal in the oak forest of Costa Rica. Serie Técnica. Informe técnico (CATIE). No. 178. 28 p.

PLATH C.V. 1967. Productive capacity of agricultural land in Central America. FAO/Rome, Italy and IICA/ Turrialba, Costa Rica. Miscellaneous Public. No. 44.

RAMIREZ J.E. 2009. Hacia la caficultura sostenible. San José, C.R, ICAFE. 216 p.

RICHARDS L.A. 1941. A pressure-membrane extraction apparatus for soil solution. Soil Science. 51:377-386.

SABORÍO J. 1992. Sistemas de información geográfica. Material de apoyo al curso de SIG. Turrialba, CR, CATIE. 39 p.

SANCHO F., CERVANTES C. 1997. El uso de plantas de cobertura en sistemas de producción de cultivos perennes y anuales de Costa Rica. Agronomía Costarricense 21(1):111-120.

SANCHO F., NÚÑEZ J. 1985. Estudio de suelos. Secciones I y II de la Cuenca del Río Parrita. San José, CR, UCR. 167 p.

SHARMA P. 1992. Material de apoyo al curso de evaluación y planificación de uso de la tierra. Turrialba, CR, CATIE. $35 \mathrm{p}$.

SHENG T.C. 1971. Proyecto de clasificación de la capacidad de la tierra orientado hacia su tratamiento para tierras marginales montañosas de los trópicos húmedos, pp.169-189. In: Memorias Seminario Latinoamericano sobre ordenación de cuencas hidrográficas. La Plata, Argentina. 22 nov.-16 dic. 1971. (mimeografiado).

SOLANO S. 2010. Potencial erosivo de las microcuencas del río Pirrís. Tesis de licenciatura, Universidad de Costa Rica, San José, Costa Rica. 147 p. 
STOORVOGEL J. 1996. El SIG como herramienta para el mapeo y uso de información edafológica, pp. 17-21. In: Memoria Congreso Nacional Agronómico y de Recursos Naturales (10), Congreso Nacional de Fitopatología (3), Congreso Nacional de Suelos (2). ¿Puede la agricultura sostenible ser competitiva?. F. Bertsch, W. Badilla, E. Bornemisza (eds.). San José, CR, EUNED/EUNA, v.3.

UGALDE M. 1996. Evaluación de suelos y tierras por medio de modelos y sistema de información geográfica, pp. 23-28. In: Memoria Congreso Nacional Agronómico y de Recursos Naturales (10), Congreso Nacional de Fitopatología (3), Congreso Nacional de Suelos (2). ¿Puede la agricultura sostenible ser competitiva?. F. Bertsch, W. Badilla, E. Bornemisza (eds.). San José, CR, EUNED/EUNA, v.3.

UREÑA E.A. 1992. Reseña histórica del Cantón de Dota. San José, Costa Rica. Ediciones Serrano Elizondo. 400 p.

VAHRSON G. 1991. Taller de erosión de suelos. Resultados, comentarios y recomendaciones. Agronomía Costarricense 15(1/2):197-203.

VAHRSON W.G., PALACIOS G. 1993. Datos complementarios de erosión, escorrentía y perdida de nutrimentos en Cerbatana de Puriscal: resultados 1991. Agronomía Costarricense 17(2):95-98. van OMME E., KAPPELLE M., JUAREZ M.E. 1997. Land cover/use change and deforestation trends over 55 years (1941-1996) in a Costa Rican montane cloud forest watershed area. Conference on Geo-Information for Sustainable Land Management ISSS-AISB-IBG, ITC. Enschede NL. 17-21.

van UFFELEN J.G. 1991. A geological, geomorphological and soil transect study of the Chirripó massif and adjacent areas, Cordillera de Talamanca, Costa Rica. Tesis de maestría, Wageningen University, Wageningen. $72 \mathrm{p}$.

VÁSQUEZ A. 1996. El ordenamiento territorial y los cambios en el uso de la tierra en Costa Rica. Agronomía Costarricense. 20(1):87-94.

USDA-NRCS (National Soil Survey Center; Natural Resource Conservation Service; US Department of Agriculture). 2002. Field book for describing and sampling soils. Lincoln, Nebraska, USA. s.p.

WALKLEY A., BLACK C.A. 1938. An examination of Degtajareffs method for determining soil organic matter and proposed modification of the chromic acid titration method. Soil Science $37: 29-38$. 